\begin{tabular}{lllllllllllllllllllllllllllllllll}
\hline$R$ & $E$ & $V$ & I & S & T & A & D & E & E & S & T & U & D & I & O & S & I & N & T & E & $R$ & N & A & C & I & O & N & A & L & E & S
\end{tabular}

\title{
In Memoriam \\ José Garrido Rojas
}

El Instituto de Estudios Internacionales de la Universidad de Chile se ha visto otra vez conmocionado por el fallecimiento de uno de sus distinguidos profesores. El Profesor José Garrido Rojas falleció en el mes de enero de 2006, luego de haber desempeñado una distinguida carrera académica y profesional.

Como profesor de la Facultad de Agronomía de la Universidad de Chile, de la cual fue también su Decano, llevó a cabo una fructífera labor académica, que en muchas de sus expresiones estuvo vinculada con la conducción de actividades y proyectos internacionales relacionados con esa especialidad. Uno de los proyectos al que dedicó especial interés fue el relativo al desarrollo de una política agrícola en el marco de los países de América Latina. En esta capacidad estuvo primero vinculado con los servicios especializados del Ministerio de Agricultura de Chile y luego con el Instituto Interamericano de Ciencias Agrícolas, en el cual realizó actividades en Lima, San José de Costa Rica y Washington D. C.

Esa dimensión internacional de su tarea fue la que determinó que, en una segunda etapa de su trayectoria académica, se incorporase al Instituto de Estudios Internacionales, donde pudo continuar desarrollando su vocación por los temas internacionales, a los cuales dedicó importantes investigaciones. Especialmente significativo fue su permanente interés por los problemas relativos al 
comercio internacional de productos agropecuarios y por la manera en que ello incidía en el desarrollo de Chile.

Notables fueron sus obras y artículos sobre la reforma agraria chilena, los problemas del indigenismo y los corredores transoceánicos entre Brasil y Chile, entre muchas otras expresiones de su vasta inquietud intelectual. Fue el Profesor Garrido un persona permanentemente preocupada de visualizar las tendencias que se proyectan hacia el futuro y de extraer las lecciones del pasado.

La experiencia adquirida por el Profesor José Garrido en el curso de sus trabajos académicos lo llevó también a vincularse con importantes actividades profesionales en el ámbito de las empresas privadas y de las organizaciones gremiales y profesionales, con particular referencia al Colegio de Ingenieros Agrónomos, del cual fue su Presidente, y a la Sociedad Nacional de Agricultura.

Sería incompleto recordar la memoria del Profesor José Garrido Rojas si no se destacara igualmente su enorme sentido de la amistad y del interés por ayudar en las labores de los demás, fueran estos los muchos alumnos que hicieron sus tesis con él o sus compañeros de labores académicas, quienes solo pueden guardar un recuerdo agradecido. Supo el Profesor Garrido cultivar el olvidado arte de la conversación, lo que también le valió el aprecio de muchos distinguidos hombres públicos de nuestro país.

En especial, debe evocarse que el Profesor José Garrido Rojas enfrentó la vida con sencillez y modestia, sin jamás caer en la vanidad que muchas veces caracteriza el quehacer académico o profesional. El Instituto de Estudios Internacionales de la Universidad de Chile le rinde al Profesor José Garrido Rojas un postrer tributo de amistad y agradecimiento.

Francisco Orrego Vicuña Heidelberg, marzo de 2006 